\title{
A interdisciplinaridade no ensino de Matemática nas séries finais do Ensino Fundamental: uma perspectiva sob a visão do licenciando
}

\author{
An interdisciplinary approach to the teaching of Mathematics in the final years of \\ Elementary School: the perspective of an undergraduate student
}

\author{
Osmano Melo Oliveira ${ }^{1}$ \\ Universidade Federal do Tocantins (UFT), Ananás, TO, Brasil \\ https://orcid.org/0000-0001-6454-3205
}

Keidna Cristiane Oliveira Souza ${ }^{2}$

Universidade Federal do Tocantins (UFT), Arraias, TO, Brasil

https://orcid.org/0000-0001-8404-7380, 9 http://lattes.cnpq.br/9847721962585782

\begin{abstract}
Leandro Luiz da Paixão ${ }^{3}$
Universidade Federal do Tocantins (UFT), Ananás, TO, Brasil

https://orcid.org/0000-0001-7769-5718, 9 http://lattes.cnpq.br/1535121558162311
\end{abstract}

\begin{abstract}
Resumo: O presente artigo discorre sobre a prática de ensino de Matemática a partir da utilização da interdisciplinaridade. Tem por objetivo evidenciar o diálogo entre as áreas do conhecimento como uma ferramenta fundamental para o ensino de Matemática. Quanto ao percurso metodológico, trata-se de um relato de experiência em uma turma de Matemática de $8^{\circ}$ ano realizado no Estágio Supervisionado que aconteceu no Colégio Estadual Presidente Castelo Branco em Nazaré, TO. Destaca-se que este trabalho se constitui em um relato de experiência que permite diálogo com outros autores, a partir de uma atividade interdisciplinar desenvolvida durante o Estágio Supervisionado, onde foram realizadas atividades como: leitura e interpretação de textos, apresentação de conteúdos em projetor multimídia, discussão dos conteúdos, resolução de problemas e atividades. Promove-se, assim, uma reflexão sobre o ensino de Matemática nas séries finais do Ensino Fundamental II, etapa em que se encontram falhas, como a dificuldade de aprendizagem e interpretação dos conteúdos, interferindo na aquisição de habilidades e competências próprias para essas idades e séries, o que dificulta a aquisição de novos conhecimentos, provocando aversão à disciplina. Percebeu-se que, quando a metodologia de ensino prioriza a elucidação da questão em uma abordagem político-social, valorizando os conhecimentos prévios dos alunos e auxiliando-os nos problemas advindos das dificuldades de interpretação de texto, por exemplo, o resultado é satisfatório: os alunos chegam às respostas e demonstram interesse pela disciplina.
\end{abstract}

Palavras-chave: Matemática; prática de ensino; conhecimento; alunos; interdisciplinaridade.

Abstract: This article discusses the teaching of Mathematics from an interdisciplinary approach. It aims at highlighting the dialogue between different areas of knowledge as a fundamental tool for teaching Mathematics. Methodologically speaking, it refers to an experience report about an 8th grade Mathematics class held during the supervised practicum that took place at Colégio Estadual Presidente Castelo Branco in Nazaré, TO. It is noteworthy that this work is an experience report that allows dialogue with other authors, from an interdisciplinary activity developed during the Supervised Internship, where activities were carried out such as: reading and interpreting texts, content presentation in a multimedia projector, content discussion, problem solving and activities. Thus, it promotes a reflection on the teaching of Mathematics in the final grades of Elementary School II, the stage in which failures occur, such as learning difficulties and the interpretation of contents, interfering with the acquisition of skills and competences specific to these ages. and grades, which makes it difficult to acquire new knowledge, causing aversion to the discipline. It was

\footnotetext{
${ }^{1}$ Currículo sucinto: Licenciado em Matemática pela Universidade Federal do Tocantins. Contribuição de autoria: Escrita - Primeira Redação.

2 Currículo sucinto: Licenciada em Matemática pela Universidade Federal do Tocantins, mestre em Matemática pela Universidade de Brasília, doutora em Matemática pela Universidade de Brasília, docente da Universidade Federal do Tocantins. Contribuição de autoria: Supervisão. Contato: keidna@uft.edu.br.

${ }^{3}$ Currículo sucinto: Licenciado em Matemática pela Universidade Federal do Tocantins. Contribuição de autoria: Escrita - Revisão e Edição. Contato: leandro.luiz@mail.uft.edu.br.
} 
noticed that, when the teaching methodology prioritizes the elucidation of the issue in a political-social approach, valuing the students' prior knowledge and helping them with problems arising from difficulties in interpreting the text, for example, the result is satisfactory: students arrive at the answers and show interest in the subject.

Keywords: Mathematics; teaching practice; knowledge; students; interdisciplinarity.

Data de submissão: 4 de Dezembro de 2020.

Data de aprovação: 1 de Julho de 2021.

\section{Introdução}

O presente estudo surgiu a partir das apreensões adquiridas por meio de observações e intervenções ocorridas na disciplina de Estágio Supervisionado, do Curso de Licenciatura em Matemática, na modalidade de Ensino a Distância (EaD), pela Universidade Federal do Tocantins (UFT), realizado no Colégio Estadual Presidente Castelo Branco, cidade de Nazaré, TO. Inicialmente, observaram-se as necessidades dos discentes e a prática de ensino do professor das turmas de Matemática do $6^{\circ}$ ao $9^{\circ}$ ano do Ensino Fundamental II.

Nessa oportunidade pôde-se constatar os obstáculos enfrentados pelos alunos na hora de interpretar e isolar os dados para a solução de problemas matemáticos, como a dificuldade de interpretação, causado principalmente pela falta de atenção a leitura. Devido a isso foram realizadas em atividades interdisciplinares com uma turma de $8^{\circ}$ ano, referente ao conteúdo de frações, que será relatada ao longo deste trabalho.

Observou-se então que as dificuldades residiam nas falhas de aprendizagem em outras disciplinas, como Língua Portuguesa, ou seja: os alunos liam mal, não conseguiam interpretar o que liam e, consequentemente, não extraiam as informações necessárias para a solução do problema matemático; com isso construíam barreiras para o aprendizado, desenvolvendo até mesmo aversão pelo estudo da Matemática por considerá-la difícil.

A partir desse ponto, surgiu a pergunta da pesquisa: A interdisciplinaridade é importante para o ensino de Matemática? Através da formulação da pergunta de pesquisa, pôde-se observar a possibilidade de realizar um trabalho que tivesse como tema a interdisciplinaridade no ensino de Matemática, cujo objetivo geral foi evidenciar um diálogo entre as diferentes áreas do conhecimento como um recurso fundamental para o ensino de Matemática. Nesse sentido, acredita-se que as habilidades e competências prévias dos alunos são de suma importância para que eles aprendam Matemática, ocorra o estímulo da capacidade cognitiva e construção do raciocínio lógico e desenvolvam interesse, enxergando-a como um ponto de partida para a compreensão do mundo à sua volta. 
Destaca-se que este trabalho se constitui em um relato de experiência que permite diálogo com outros autores, a partir de uma atividade interdisciplinar desenvolvida durante o Estágio Supervisionado, como mencionado anteriormente, onde foram realizadas atividades como: leitura e interpretação de textos, apresentação de conteúdos em projetor multimídia, discussão dos conteúdos, resolução de problemas e atividades. Os objetivos específicos da pesquisa buscam: (i) refletir sobre a prática de ensino que priorize a interdisciplinaridade no ensino de Matemática, posteriormente, avaliar como a Base Nacional do Ensino Médio (BNCC) tem abordado a interdisciplinaridade no ensino de Matemática; (ii) valorizar o diálogo entre as diferentes disciplinas; (iii) compreender em que medida essas novas propostas de ensino levam o aluno a ter interesse para a produção de novos saberes no campo matemático.

Observou-se que, mesmo o professor instigando o aluno, muitos ainda têm uma dificuldade real e um pouco de resistência frente ao conhecimento matemático, contudo, percebeu-se que essa resistência não é proposital, mas é oriunda de falhas como a dificuldade de aprendizagem e interpretação dos conteúdos, interferindo na aquisição de habilidades e competências próprias para essas idades e séries, o que dificulta a aquisição de novos conhecimentos, provocando aversão à disciplina. Além disso, no processo de ensino e aprendizagem até aquele momento do saber, há perdas na qualidade do ensino, advindas de abordagens metodológicas que não foram capazes de envolver o aluno e despertar o seu interesse.

Segundo dados do Instituto Nacional de Estudos e Pesquisas Educacionais Anísio Teixeira - INEP (OLIVEIRA, 2019), o Brasil é classificado como o pior país em Matemática, perdendo somente para Argentina, com 384 e 379 pontos, respectivamente. Uruguai (418), Chile (417), Peru (400) e Colômbia (391) estão à frente.

O estudo da Matemática é extremamente necessário à vida do indivíduo que a utilizará mais do que imagina, pois seu aprendizado está diretamente ligado ao desenvolvimento do ser humano, uma vez que ela está presente no seu dia a dia, mesmo que ele a utilize de maneira automática e nem perceba, sedo capaz de estruturar os ser humano em múltiplas atividades diárias que são necessárias o uso do raciocínio lógico, em muitas atividades diárias tem a necessidade do uso do conhecimento matemático, como: em formas, valores, tamanhos, quantidades, pesos, dentre outros. Devido a isso, a Matemática é indispensável na formação profissional do aluno, visto que ela desenvolve o raciocínio do estudante para que este utilize-o dentro e fora da sala de aula.

Espera-se, com este trabalho, tornar evidente o quanto o ensino de Matemática precisa ser significativo ao Ensino Fundamental especificamente ao $8^{\circ}$ ano, para acolher as diferenças existentes em sala de aula, e aplicar uma metodologia de ensino que consiga ampliar os 
horizontes dos alunos, de modo a melhorar a qualidade de ensino, despertar o interesse, destacando a participação discente como elemento fundamental na produção do conhecimento.

\section{Interdisciplinaridade: explorando o conceito e sua aplicabilidade no meio educacional}

Segundo Klein (1998 apud GARCIA, 2008), o surgimento do termo interdisciplinaridade se deu no século XX e compreender o contexto do seu surgimento é fundamental, pois possibilita a melhor compreensão da temática:

A palavra interdisciplinaridade é uma invenção do século $X X$. Seus primeiros registros ocorreram nos Estados Unidos, no debate sobre a importância do diálogo entre as áreas do conhecimento em ciências sociais (KLEIN, 1998) De um modo mais amplo, pode-se afirmar que a interdisciplinaridade é um fenômeno do século passado, enraizado nas reformas educacionais modernas, na pesquisa aplicada e nos esforços para dissolver barreiras disciplinares. (GOZZER, 1992; KLEIN, 1998 apud GARCIA, 2008, p. 364).

Conforme se observa na citação acima, o conceito de interdisciplinaridade nasceu nos Estados Unidos, a partir um debate sobre a importância de fomentar o diálogo entre as diferentes áreas do conhecimento; constata-se que apesar de ser um conceito do século passado, há muito que se fazer para que de fato seja efetivada na prática de ensino das instituições brasileiras, porque a realidade de muitas escolas ainda apresenta diversos obstáculos ao aprendizado do aluno, como a falta de recursos e materiais diversos, que podem ser desde itens de limpeza até ferramentas de ensino essenciais, como computadores funcionais e com acesso à internet.

É importante destacar que as discussões sobre interdisciplinaridade assumiram duas perspectivas. Uma delas, mais relacionada à discussão epistemológica, produziu avanços ao explorar aquele conceito como um diálogo integrativo entre diferentes disciplinas, entendidas como campos do conhecimento. A outra perspectiva refere-se aos desenvolvimentos relacionados ao currículo da educação básica, na forma de estratégias para a integração entre disciplinas, aqui entendidas como as matérias do currículo escolar. (GARCIA, 2008, p. 365).

Garcia (2008), acima citado, destaca que, em relação à proposta da interdisciplinaridade, desenvolveram-se debates com perspectivas distintas, uma se preocupou com o currículo escolar, enquanto a outra se ateve à teoria do conhecimento propriamente dita, ocupando-se com a relação entre o conhecimento e seus métodos.

Para Libâneo (1994), que escreveu sobre o termo interdisciplinaridade, cuja definição é aquela que se pretende ater durante esta pesquisa, é um conceito fundamental para que o diálogo seja proveitoso. Segundo o autor:

A noção mais conhecida de interdisciplinaridade é a de interação entre duas ou mais disciplinas para superar a fragmentação, a compartimentalização, de conhecimentos, implicando uma troca entre especialistas de vários campos do conhecimento na discussão de um assunto, na resolução de um problema, tendo em vista uma compreensão melhor da realidade. (LIBÂNEO, 1994, p. 14). 
Compreensão melhor da realidade, eis aqui o ponto base da pesquisa! O autor argumenta que é necessário haver uma interação entre duas ou mais disciplinas, para que se possa superar a fragmentação dos conhecimentos e, para que isso ocorra, é preciso uma cumplicidade entre especialistas de áreas distintas. Do ponto de vista da pesquisa, espera-se estreitar os laços na produção do conhecimento entre as disciplinas de Língua Portuguesa e Matemática, avaliando que medida o diálogo entre elas promove uma melhor interpretação e solução dos problemas matemáticos.

Para Paulo Freire (2001 apud FERNANDES, 2017, p. 3): "a interdisciplinaridade é o processo metodológico de construção do conhecimento pelo sujeito, com base em sua relação com o contexto, com a realidade, com sua cultura". A partir dessa citação, é possível perceber o quanto é importante a adoção da abordagem interdisciplinar, pois consiste em ser um meio que busca contextualizar o processo de ensino valorizando a cultura e a realidade discente, ou seja, uma forma acolhedora que suaviza as diferenças e amplia as convergências.

A existência, tanto do aluno, quanto dos professores, está interligada, não é possível a existência de um sem o outro. O professor, como qualquer outro ser humano, é um ser inacabado que está sempre em processo de construção, sujeito a erros e acertos. É preciso ter um bom senso em ponderar, estimular, cobrar e analisar, tanto a si mesmo, quanto a seus alunos. (FREIRE, 1996, p. 63).

Na citação acima, Freire (1996) levanta uma questão interessante: o aprendizado mútuo e constante entre professor e aluno. Essa visão é importante porque rompe com a figura autoritária do professor que tudo sabe, estabelece uma imagem de um profissional que se percebe como inacabado, e se propõe a construir saberes em sala de aula instigando o aluno frente novos conhecimentos e o orientando a aprender cada vez mais e melhor, fomentando sua curiosidade e ações colaborativas entre os diversos saberes possíveis, dentro e fora da escola.

Para Tomaz (2008), autor que também discorre sobre a temática interdisciplinaridade:

Embora a multiplicidade de fatores acene para a interdisciplinaridade como uma solução para os limites $e$ as incapacidades das disciplinas isoladas de compreender a realidade e responder às demandas do mercado de trabalho, na prática, difunde-se ainda na maioria das escolas um conhecimento fragmentado, deixando para o aluno estabelecer sozinho as relações entre os conteúdos. (TOMAZ, 2008, p. 13).

Tomaz (2008) chama a atenção para a questão de que não se pode encarar a interdisciplinaridade como solução para todos os problemas da educação. Ele especificamente, fala das incapacidades das disciplinas isoladas poderem atender às demandas do mercado de trabalho. Para a autora, a prática está bem distante da realidade, ou seja, o trabalho de estabelecer as relações entre os conteúdos ainda fica à cargo dos alunos, em uma tarefa solitária. Percebe-se que as escolas ainda não estão conseguindo tornar tal abordagem uma prática de sucesso e assim vivenciar os benefícios metodológicos proporcionados por ela, embora reconheçam a importância do diálogo entre as diferentes áreas do conhecimento. 
$\mathrm{Na}$ interdisciplinaridade, as relações ocorrem em dois níveis, com relações e influências recíprocas, a colaboração entre as diversas disciplinas conduzem a uma interação, um diálogo que caminha para uma estruturação de conceitos englobando todo o conhecimento envolvido numa síntese. Nesta abordagem teremos inicialmente olhares diferentes para um mesmo objeto, mas que resultarão em modificações no modo de ver este objeto, com enriquecimentos epistemológicos para todos. (SERENATO, 2008, p. 43).

Os professores de Matemática do Colégio Estadual Presidente Castelo Branco, que ministram aulas do $6^{\circ}$ ao $9^{\circ}$ e no Ensino Médio, em conversa informal, observaram que a proposta de ensino interdisciplinar não tem sido vivenciada em todas as suas possibilidades, pois, além das dificuldades de o aluno aprender a disciplina, ele se sente frustrado porque houve uma defasagem em séries anteriores, fato que hoje lhe prejudica na interpretação dos problemas matemáticos.

Felicetti (2010), ao argumentar sobre as dificuldades dos alunos, fez um apelo à abordagem metodológica do professor, destacando a importância da criatividade no exercício da profissão e o papel social das disciplinas, cujo objetivo é proporcionar ao aluno o ato de pensar, tornando-o não só um aluno, mas um cidadão crítico, segundo a orientação docente: Para o referido autor,

[...] a maioria dos alunos acha que não gosta de Matemática porque os professores não sabem ensinar a matéria. A Matemática deveria ser ensinada pelo professor, utilizando-se da criatividade, pois não é uma disciplina feita para calcular, mas para pensar. [...] não associam a Matemática da escola com a Matemática do cotidiano. Parece que a Matemática serve somente para "passar de ano" na escola e nada mais. (FELICETTI, 2010, p. 34).

As considerações feitas por Felicetti (2010) apontam que muitos alunos acreditam que não gostam de Matemática; tonando perceptível que, se eles acham, é porque não têm certeza, logo, suspeitando que há algo de errado com o ensino dessa disciplina. Desse modo, conclui-se que, tendo em vista que a utilização de Matemática será necessária ao longo de sua vida, e que está presente em todos os lugares, é fundamental que os alunos aprendam e façam bom uso dela e que sejam bem orientados por seus professores.

Ainda de acordo com Felicetti (2010), parafraseando suas ideias, a Matemática foi feita para pensar e não para calcular, ou seja, para usar o raciocínio lógico. A afirmação anterior nos leva a uma reflexão sobre o ensino de Matemática, pois concordando com Felicetti, os alunos não veem sentido na disciplina Matemática além da sala de aula, e para passar de ano. É fundamental que os professores consigam transcender essa realidade através de um ensino interdisciplinar.

Os autores Fontes, Contijo e Moreira (2019) fazem uma crítica à organização do ensino contemporâneo. Trata-se de uma crítica relevante, porque os professores se orientam segundo a forma pela qual o ensino é organizado:

De acordo com nossos referenciais, esse modo de organizar o ensino é limitante, e não condiz com as necessidades educativas atuais. A interdisciplinaridade apresenta-se como uma possibilidade para superar esse modelo, mas para que as mudanças curriculares ocorram, é preciso que elas perpassem a formação de 
professores, pois os licenciados tendem a reproduzir, em suas salas de aula, suas práticas formativas. (FONTES; CONTIJO; MOREIRA, 2019, p. 61).

A partir da análise da citação acima, observa-se que apesar da interdisciplinaridade ser vista como uma possibilidade, os autores acreditam que a organização do ensino não está absorvendo as necessidades da educação atualmente, sugerindo, desse modo, que haja maior preocupação com a formação docente.

A formação docente é um ponto fundamental para o exercício da interdisciplinaridade em sala de aula, porque o professor é o orientador de seus alunos, ou seja, ele vai conciliar contextos e temáticas para oferecer uma aula que desperte a vontade do aluno em buscar de algo mais, porque educação é isso: ensinar a questionar e construir, e nunca impor modos de agir e pensar.

Para mostrar que há possibilidade de uma estrutura curricular não linear e mais aberta à interdisciplinaridade, tomamos os exemplos apresentados por Silva e Pires (2013), que têm como critério de organização a recursão: o currículo em espiral, o currículo em rede e o currículo fractal. O currículo em espiral é planejado de modo a possibilitar o retorno às ideias básicas, até que o aluno tenha captado completamente e intuitivamente os conceitos matemáticos. Esse modo de organização curricular enfatiza a necessidade de compatibilizar os pensamentos intuitivo e analítico, de modo que ambos estejam em harmonia. No currículo em rede, a ideia central é que não existe caminho certo, mas diversos caminhos, cada uma com sua riqueza de informações e possibilidades. (FONTES; CONTIJO; MOREIRA, 2019, p. 66).

Fontes, Contijo e Moreira (2019), conforme citação acima, depois de terem identificado falhas na organização do ensino e criticado a grade curricular, demonstram de que forma seria possível superar essa dificuldade e argumentam que o currículo não precisa ser linear. Os autores trazem para o debate exemplos do ano de 2013, como o currículo em espiral, em rede e o fractal, conforme discriminado acima. É bom observar que os estudiosos apresentam alternativas viáveis para o ensino, porque, apesar das inúmeras dificuldades, fica a esperança de que a interdisciplinaridade ganhe forças para proporcionar um ensino atento à realidade e necessidades dos alunos, pois, segundo Tavares (2018, p. 7):

Se pensarmos na educação como um processo de desenvolvimento harmônico de todas as capacidades físicas, mentais, intelectuais e espirituais, podemos alcançar as mais diversas formas de viver intensamente a interdisciplinaridade, no campo social, ético, cultural, político, econômico, entre outros. Aí teremos uma visão clara da amplitude da interdisciplinaridade, porque ela abarca, não só a visão formativa do indivíduo, mais se estende nas mais diversificadas áreas do conhecimento.

Hadassah (2018) traz para o debate argumentos que corroboram com a postura de Tavares (2018):

A Interdisciplinaridade, como diz o texto, se apresenta como uma solução para a contemporaneidade, diante das complexidades de necessidade de coesão social, participação democrática, desenvolvimento humano, e a necessidade de ensinar tanto contextos artísticos como científicos. Dessa forma, o ensino reflexivo crítico, promovido pela Interdisciplinaridade, desenvolve professores e pesquisadores que rompem com a dicotomia educação e ciência através de um conceito ininterrupto que visa permear toda a vida em seu entorno. Aponta para uma nova maneira de 
fazer ciência e educação afim de atender aos interesses socioculturais, respeitando as características intrínsecas individuais e coletivas para seu desenvolvimento. (HADASSAH, 2018, p. 97).

Falar em interdisciplinaridade transcende a questão escolar, pois como elemento fundamental para a educação, pode ser observada em todas as relações humanas, e conforme seus preceitos, foi pensada para o exercício da cidadania, para o desenvolvimento de alunos que pensam e atuam. Afinal, aprendemos para compartilhar, e compartilhamos para nos aprimorar. Uma forma de ampliar conhecimentos é permitir relações entre as diferentes áreas da aprendizagem.

Silva e Fazenda (2018, p. 14) destacam que:

Esta busca por mudanças nos leva a romper com as barreiras entre as disciplinas, por meio do diálogo constante entre professores, e criação de projetos coletivos em que todos possam trabalhar integrando teorias, métodos e práticas. Isto é no mínimo uma tarefa difícil, pois significa modificar a prática e o funcionamento das escolas em que trabalhamos e da sociedade em que estamos inseridos. Significa a substituição de uma concepção fragmentária e individualista do ser humano, para uma visão do ser humano em constante processo de transformação que necessita da interação social para se desenvolver.

As autoras acima destacam que buscar por mudanças é o que favorece o rompimento das barreiras entre as disciplinas, proporciona o diálogo que deve ser constante entre os professores e trazem a afirmação maravilhosa de que o ser humano encontra-se em constante processo de transformação, e isso nos leva a refletir sobre a seguinte questão: se todos os homens estão, a cada dia, evoluindo um pouco mais, por que a educação, desses mesmos homens, pode supor-se estagnar em um ponto no qual segmenta os saberes?

\section{A interdisciplinaridade no ensino de Matemática nas séries finais do Ensino Fundamental e os Parâmetros Curriculares Nacionais}

Debater-se-á neste tópico a interdisciplinaridade a partir dos Parâmetros Curriculares Nacionais - PCNs e a Base Nacional Comum Curricular - BNCC, visto que as PCNs oferecem diretrizes fundamentais para a organização dos currículos do Ensino Fundamental. Nesse sentido, uma discussão acerca do diálogo entre duas ou mais disciplinas não pode deixar de abordar os PCNs.

A interdisciplinaridade questiona a segmentação entre os diferentes campos de conhecimento produzido por uma abordagem que não leva em conta a interrelação e a influência entre eles questiona a visão compartimentada (disciplinar) da realidade sobre a qual a escola, tal como é conhecida, historicamente se constitui. Refere-se, portanto, a uma relação entre disciplinas. (BRASIL, 1998, p. 31).

Observa-se, segundo os PCNs, que a interdisciplinaridade promove o questionamento da segmentação entre as áreas do conhecimento, como um documento regulatório do Currículo Nacional, esse questionamento se torna abrangente e propõe que se repense a prática 
metodológica, pois, segmentar os saberes é o mesmo que expropriar o conhecimento, uma vez que as diferentes áreas de novos saberes possuem uma relação fundamental para a produção dentro da sala de aula, ignorar essa relação é negar ao aluno a oportunidade de articular saberes, dificultando o ensino de Matemática.

Sobre a importância da relação entre as disciplinas discorre Zabala (2002, p. 35):

A interdisciplinaridade é a interação de duas ou mais disciplinas, que pode ir desde a simples comunicação de ideias, até a integração recíproca dos contextos fundamentais e da teoria do conhecimento, da metodologia e dos dados de pesquisa. Estas interações podem implicar transferências de leis de uma disciplina para outra e, inclusive, em alguns casos dão lugar a um novo corpo disciplinar, como a bioquímica ou a psicolinguística. Podemos encontrar esta concepção na configuração das áreas de Ciências Sociais e Ciências Experimentais no ensino médio e da área de Conhecimento do meio no ensino fundamental.

Zabala (2002) fala em "reciprocidade" e chama a atenção para o surgimento de áreas do conhecimento que já foram novas, que não poderiam existir sem esse estreito diálogo de disciplinas, hoje, conforme citação acima há duas disciplinas chamadas Psicolinguística e Bioquímica, que são frutos da junção de disciplinas preexistentes e que exercem um papel importante na sociedade, e muito tem a contribuir para com a humanidade.

É indispensável que o corpo docente abrace a causa, questione, sensibilize e cobre os gestores de todas as esferas públicas, para que lhes proporcionem meios de exercer sua função com dignidade e criatividade, no seu papel de formar cidadãos críticos, pois o professor sozinho não consegue oferecer uma excelente prática de ensino.

Interdisciplinaridade é um objetivo que nunca é completamente alcançado, e por isso deve ser permanentemente buscado. Não é apenas uma proposta teórica, mas, sobretudo uma prática. Sua perfectibilidade é realizada na prática; na medida em que são feitas experiências reais de trabalho em equipe [...]. (SANTOMÉ, 1998, p. 66).

Apesar de ser do ano de 1998, a citação acima é atualíssima! Também de 1998 são os PCNs de $5^{a}$ a $8^{a}$ série do Ensino Fundamental, disponíveis para download na plataforma do Governo Federal, onde encontram-se as seguintes citações:

A compreensão das questões ambientais pode ser favorecida pela organização de um trabalho interdisciplinar em que a Matemática esteja inserida. A quantificação de aspectos envolvidos em problemas ambientais favorece uma visão mais clara deles, possibilitando tomar decisões e fazer intervenções necessárias (reciclagem e reaproveitamento de materiais, por exemplo). (BRASIL, 1998, p. 31).

Acima, percebe-se, claramente a recomendação da proposta interdisciplinar, todavia, sabe-se que, em sala de aula, ela está longe de ser alcançada da forma como é regulamentada e projetada, isto porque, não obstante o Governo Federal possuir todos os meios para prover e fiscalizar as instituições de ensino, delegando essa tarefa aos Governos Estaduais como forma de descentralizar as ações, constata-se que as escolas públicas continuam sucateadas em suas necessidades básicas, o que inviabiliza, inclusive, a liberdade de pensamento e a livre docência. 
Ainda nos PCNs de Matemática, seguem mais recomendações de mesma natureza interdisciplinar:

Os conteúdos do bloco Tratamento da Informação podem ser explorados em projetos mais amplos, de natureza interdisciplinar, que integrem conteúdos de outras áreas do currículo, como a História e a Geografia, além da Matemática e os temas como Saúde e Meio Ambiente. O tema Trabalho e Consumo, por exemplo, é um bom eixo para articular um desses projetos, uma vez que esse assunto é de grande interesse dos alunos, principalmente os de quarto ciclo, que começam a tomar algumas decisões em relação ao seu encaminhamento profissional. (BRASIL, 1998, p. 138).

Quando os PCNs abordam a questão da interdisciplinaridade, percebe-se que também estão oferecendo modelos para o docente trabalhar em sala de aula, conforme citado acima, quando se fala em áreas afins. Ressalta-se ainda que essa abordagem se configura como uma forma de despertar o interesse do aluno para o aprendizado. Foi possível observar que Colégio Estadual Presidente Castelo Branco não possui nenhum documento indicando que os professores realizam ações interdisciplinares com os alunos.

A abordagem interdisciplinar, bem realizada, tem por finalidade envolver o aluno e proporcionar a ele o prazer em estudar. Esse é o caso do ensino de Matemática, pois ela pode ser amada e aprendida de forma a dar significado para vida em sociedade, pode ser uma agente transformadora da realidade do aluno.

Fica claro o papel fundamental do professor em sala de aula, pois cabe a ele diagnosticar os problemas que dificultam o aprendizado, e procurar meios de superá-los, não esquecendo o papel da comunidade escolar que é composta também pela família. A família precisa participar e ajudar nessa construção de conhecimento, pois a escola não é composta apenas por professores e alunos, mas envolve toda a gestão da educação: coordenador, diretor, secretario, dentre outros.

\section{A Base Nacional Comum Curricular e a proposta interdisciplinar para os anos finais do Ensino Fundamental: evidência para o ensino de Matemática}

O que é BNCC? Trata-se da Base Nacional Comum Curricular, documento previsto pela Lei de Diretrizes e Bases da Educação de 20 de dezembro de 1996. De forma obrigatória, ela regula quais conhecimentos e habilidades os alunos de determinada fase de ensino devem possuir e define seus direitos em âmbito nacional.

Segundo consta na apresentação da obra, a elaboração do documento contou com a colaboração de profissionais de todas as áreas do conhecimento, assegurando-se a completude e contemporaneidade do mesmo, entretanto:

A BNCC por si só não alterará o quadro de desigualdade ainda presente na Educação Básica do Brasil, mas é essencial para que a mudança tenha início porque, além dos currículos, influenciará a formação inicial e continuada dos educadores, a produção de materiais didáticos, as matrizes de avaliações e os 
exames nacionais que serão revistos à luz do texto homologado da Base. (BRASIL, 2017, p. 5).

Segundo a citação anterior, a Base Nacional Comum Curricular não altera o quadro de desigualdades vigente, pelo menos não por si só, como foi destacado. Apreende-se com isso que há uma necessidade de articulação entre as esferas do poder, para elaboração também de políticas públicas eficientes e que dialoguem entre si, para a superação das desigualdades e marginalizações sociais.

Em relação às competências gerais para a Educação Básica, são elencadas dez na BNCC, contudo, destacam-se algumas de grande relevância para esse estudo:

\begin{abstract}
Valorizar a diversidade de saberes e vivências culturais e apropriar-se de conhecimentos e experiências que Ihe possibilitem entender as relações próprias do mundo do trabalho, e fazer escolhas alinhadas ao exercício da cidadania e ao seu projeto de vida, com liberdade, autonomia, consciência crítica e responsabilidade. (BRASIL, 2017, p. 9).
\end{abstract}

Se for observada de perto, a competência acima destacada, é possível compreender que o princípio da interdisciplinaridade se encontra implícito, pois, apesar de abordar a questão do mundo do trabalho, ou seja, preparar o aluno para uma vida profissional, ela deixa subentendida a importância da valorização da história de vida desse aluno. Nesse sentido, percebe-se que as áreas do conhecimento se encontram interligadas, e são complementares e necessárias para que o indivíduo se torne pleno em diversos aspectos de sua vida, momento no qual o conhecimento adquirido na sala de aula irá transpor os muros das instituições de ensino e cumprir o seu papel de formar um cidadão crítico e atuante.

Ainda de acordo com a BNCC (BRASIL, 2017), em relação às competências: "conhecer-se, apreciar-se e cuidar de sua saúde física e emocional, compreendendo-se na diversidade humana e reconhecendo suas emoções e as dos outros, com autocrítica e capacidade para lidar com elas" (BRASIL, 2017, p. 10). A partir do exposto, acredita-se que essa competência é de grande importância, porque aborda a questão do respeito recíproco, ou seja, quando a pessoa conhece a si mesma, ela aprende a lidar com as suas emoções e com as dos outros, ela está exercendo o princípio da alteridade e se colocando no lugar do outro, o que fomenta o diálogo tão necessário às relações humanas e culmina na empatia.

A próxima competência complementa a supracitada:

Exercitar a empatia, o diálogo, a resolução de conflitos e a cooperação, fazendose respeitar e promovendo o respeito ao outro e aos direitos humanos, com acolhimento e valorização da diversidade de indivíduos e de grupos sociais, seus saberes, identidades, culturas e potencialidades, sem preconceitos de qualquer natureza. (BRASIL, 2017, p. 10).

A partir do quarto tópico é que a BNCC começa a abordar a temática do Ensino Fundamental, que faz parte do objeto de estudo desta pesquisa: 
O Ensino Fundamental, com nove anos de duração, é a etapa mais longa da Educação Básica, atendendo estudantes entre 6 e 14 anos. Há, portanto, crianças e adolescentes que, ao longo desse período, passam por uma série de mudanças relacionadas a aspectos físicos, cognitivos, afetivos, sociais, emocionais. (BRASIL, 2017, p. 57).

Aspecto interessante, destacado acima, é a variação das idades compreendidas nesses nove anos que compõem o Ensino Fundamental. O documento da BNCC (BRASIL, 2017) destaca ainda que existem muitos aspectos envolvidos nesse processo de aprendizagem. Em momentos de mudanças, os alunos precisam ser acolhidos e orientados rumo ao conhecimento.

É uma tarefa bem difícil, se for considerada a escassez de recursos que as escolas brasileiras enfrentam atualmente, e ainda se for levado em conta que também os docentes se aborrecem com essa situação, entre elas a falta de reconhecimento, salários baixos e a falta de segurança física no exercício da profissão.

O conhecimento matemático é necessário para todos os alunos da Educação Básica, seja por sua grande aplicação na sociedade contemporânea, seja pelas suas potencialidades na formação de cidadãos críticos, cientes de suas responsabilidades sociais. (BRASIL, 2017, p. 265).

A BNCC (BRASIL, 2017) destaca ainda que a Matemática é importante para além da sala de aula, influenciando, inclusive, na formação de cidadãos críticos. Esse aspecto da disciplina de Matemática acaba sendo relegado a segundo plano, devido às deficiências adquiridas pelos alunos, quer seja pelo fracasso da metodologia de ensino adotada, ou por suas próprias mazelas sociais que, em geral, não são contempladas pelas políticas públicas vigentes e eclodem na sala de aula.

Apesar de a Matemática ser, por excelência, uma ciência hipotético-dedutiva, porque suas demonstrações se apoiam sobre um sistema de axiomas e postulados, é de fundamental importância também considerar o papel heurístico das experimentações na aprendizagem da Matemática. (BRASIL, 2017, p. 265).

A citação acima reforça o fundamental papel da disciplina de Matemática que é instigar o aluno a buscar o conhecimento, a realizar descobertas a partir de uma diretriz. A Matemática é necessária ao indivíduo por toda a sua vida.

O Ensino Fundamental deve ter compromisso com o desenvolvimento do letramento matemático, definido como as competências e habilidades de raciocinar, representar, comunicar e argumentar matematicamente, de modo a favorecer o estabelecimento de conjecturas, a formulação e a resolução de problemas em uma variedade de contextos, utilizando conceitos, procedimentos, fatos e ferramentas matemáticas. É também o letramento matemático que assegura aos alunos reconhecer que os conhecimentos matemáticos são fundamentais para a compreensão e a atuação no mundo e perceber o caráter de jogo intelectual da matemática, como aspecto que favorece o desenvolvimento do raciocínio lógico e crítico, estimula a investigação e pode ser prazeroso (fruição). (BRASIL, 2017, p. 266).

Encerra-se esse tópico com uma reflexão sobre o quanto o ensino de Matemática pode transformar realidades e contribuir para com uma sociedade mais justa e igualitária, uma vez que 
ela é de fundamental importância na formação de cidadãos críticos e atuantes. Portanto, é indispensável que haja mais esforços no sentido de despertar o interesse do discente, que haja diálogo entre os sujeitos do processo educacional, que a interdisciplinaridade seja uma constante no sentido de facilitar a relação entre ensino e aprendizagem, além de fomentar o diálogo entre as áreas do conhecimento.

\section{Relato de experiência em uma turma de $8^{\circ}$ ano de Matemática no Colégio Estadual Presidente Castelo Branco em Nazaré, TO}

Durante o Estágio Supervisionado, ministrou-se uma aula que abordou o tema de frações no $8^{\circ}$ ano na Escola Estadual Presidente Castelo Branco, em Nazaré, TO. Durante a elaboração do plano de aula, depois de observar que alguns alunos ficavam atentos aos conceitos básicos e necessários para o entendimento do conteúdo, planejou-se, como forma de favorecer o ambiente para a aprendizagem dos alunos, realizando uma aproximação junto à turma, propostas para uma aula diferenciada e descontraída, foi então surgiu à ideia da pizza confeccionada em papel cartão.

O principal objetivo de utilizar a pizza foi que, de maneira interdisciplinar, ela proporcionou relembrar o conteúdo de frações de uma forma bem receptiva; por ela ter sido confeccionada em papel cartão, envolveram-se conhecimentos de Artes Visuais apreendidos nas primeiras séries do Ensino Fundamental II, e ao mesmo tempo conhecimentos matemáticos, pois é um desenho que possui figuras geométricas e que cada pedaço de pizza é um setor circular, e ela inteira representa um círculo. Foi solicitado que os alunos pegassem uma das fatias e tentassem relacioná-la com o todo, com o intuito de envolver as Artes Visuais com a Matemática. Em seguida, também somaram as partes retiradas para obter o valor de três oitavos.

A pizza é um dos alimentos favoritos dos adolescentes, e só em falarmos sobre ela já chamaria a atenção dos alunos. Desse modo: desenhou-se e pintou-se em papel cartão uma pizza grande com oito fatias; primeiramente, mostrou-se para todos do que se tratava, em seguida, perguntou-se se alguém sabia onde a pizza havia sido criada, alguns alunos afirmaram se tratar de um alimento de origem italiana e assim iniciou-se a conversa envolvendo a questão da Matemática em que foi perguntado à turma: essa pizza inteira como está no papel, se falarmos em relação ao nosso conteúdo de hoje que são frações, ela representa o quê? Houve um pouco de silêncio e depois de algum tempo um aluno respondeu: "um inteiro!".

A dinâmica continuou e passou-se a utilizar a tesoura para fatiar a maquete da pizza, conforme as marcações no papel, e retirando-se apenas uma fatia, foi perguntado o que ela representava, considerando que fazia parte de um total de oito fatias, e alguém respondeu: "um oitavo!". E assim a aula prosseguiu, de maneira prazerosa, com os alunos participando e discutindo conceitos, porque para entender a simplificação de frações, se eles não 
compreendessem o básico, ficaria inviável, pois a turma não seguiria no mesmo nível de compreensão.

Foi uma atividade bem proveitosa, porque os alunos se divertiram bastante, brincaram de comer a pizza fictícia, e aqueles que estavam mais atrasados e quietinhos passaram a participar. Percebeu-se que eles demonstraram curiosidade em compreender coisas como a origem da pizza, que envolve conhecimentos de Geografia e História, e depois retornaram para o tema, também foi perguntado de que forma eles souberam da origem da pizza: uns disseram que leram (leitura e interpretação, habilidades da Língua Portuguesa) e outros que parentes Ihes contaram, e ainda teve gente que comentou que não sabia. Aproveitando a ocasião, falou-se de como as áreas do conhecimento se completam, por exemplo: para ler é preciso ter estudado Língua Portuguesa e no caso de ter ouvido uma história que foi passada de uma pessoa para outra, ao longo do tempo, se tratava de história oral, e assim a curiosidade deles foi sendo aguçada para que pudessem participar.

Abaixo, encontra-se a Figura 1 contendo o desenho da pizza, da forma como se ilustrou em sala de aula.

Figura 1 - Relembrando frações com pizza.

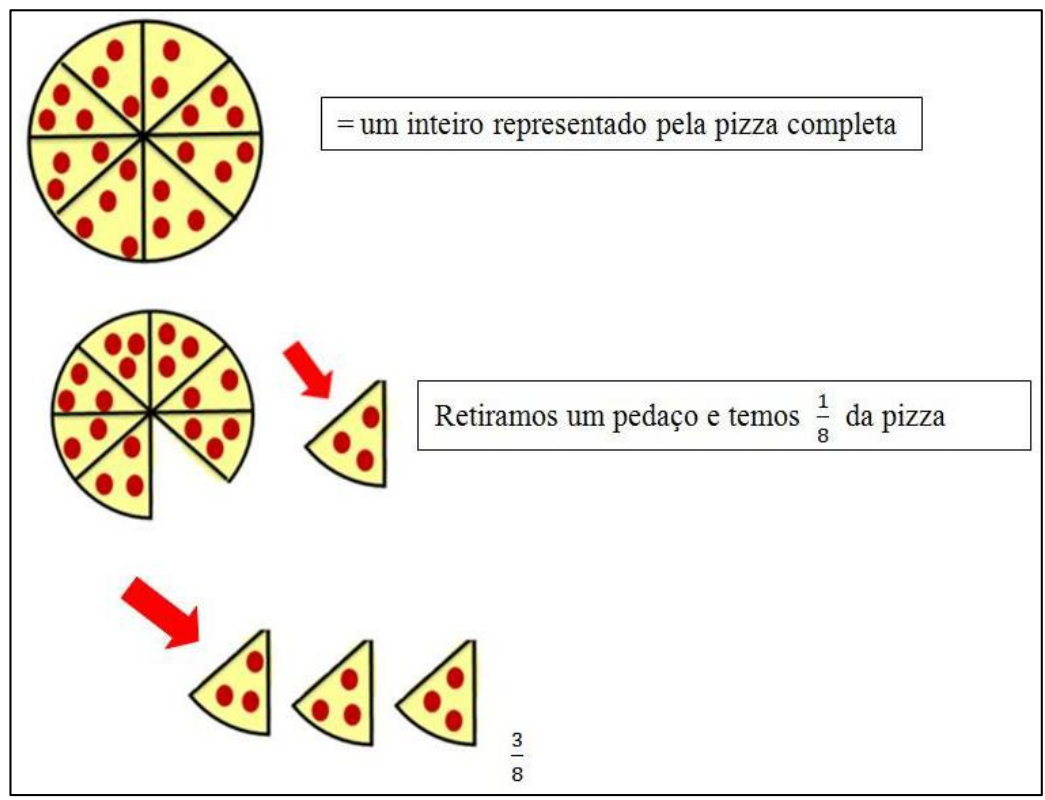

Fonte: Elaborado pelos autores (2020).

\section{Reflexões pós-pesquisa}

Essa pesquisa foi importante para o crescimento acadêmico, uma vez que proporcionou aos professores uma ampla reflexão acerca do ensino de Matemática, compreendendo-a de maneira clara e sucinta, podendo proporcionar aos alunos o exercício de sua cidadania. Quando 
esse exercício se efetiva, através do ensino de Matemática, percebeu-se que os estudantes foram além da sala de aula e oferecem contribuições junto à sociedade. Verificou-se, portanto, a importância da formação docente vivenciada na prática pelos futuros professores, não apenas de forma teórica.

Foi pensando nisso que, em uma aula sobre frações, os pesquisadores se propuseram a ministrá-la de forma interdisciplinar, a fim de auxiliar os alunos que apresentavam dificuldades básicas nos conceitos simples. Desse modo, a partir de uma brincadeira com uma pizza feita em papel cartão, foi possível tornar o ambiente mais acolhedor para o conhecimento e assim os alunos participaram bastante da aula com perguntas e contribuições.

Foi possível observar, enquanto futuros educadores, que a forma como o ensino de Matemática ocorre em sala de aula influencia o interesse dos alunos; que ensinar através da articulação entre as diferentes áreas do conhecimento é importante também para contribuir para com uma sociedade atuante, visto que a Matemática oferece diretrizes para o crescimento pessoal ao possibilitar um olhar reflexivo.

A interdisciplinaridade para o ensino de Matemática é fundamental, assim como para as outras disciplinas, porque não é vantajoso segmentar as áreas do conhecimento de tal forma que a essência de uma se perca na outra. Um olhar interdisciplinar favorece o exercício da cidadania e auxilia a escola a cumprir o seu papel de formadora de cidadãos críticos e atuantes junto à sociedade.

\section{Considerações finais}

Acredita-se que a pergunta formulada para essa pesquisa, no início do trabalho, foi respondida, pois argumentou-se de forma a comprovar que a interdisciplinaridade é importante para a metodologia de ensino de Matemática, uma vez que ela favorece a atitude reflexiva e leva o aluno a descobrir o mundo por si próprio. Nesse sentido, o aluno poderá ser capaz de compreender que a Matemática está em toda parte, que ela permeia e permeará o cotidiano, por toda a sua vida, quer seja dentro ou fora das instituições de ensino.

Os objetivos foram alcançados, pois houve a preocupação, ao longo da pesquisa, em refletir sobre a prática de ensino docente, evidenciando os obstáculos que são encontrados para a realização do seu trabalho, também buscou-se a valorização da metodologia de ensino que priorize o diálogo entre as disciplinas, de forma que uma complemente a outra, e principalmente, destacou-se o quanto é indispensável despertar o aluno para a produção do conhecimento por meio da valorização da história de vida, evidenciando que o ensino da Matemática pode ser prazeroso e significativo, e que é um norte para outras descobertas. 
Após análise dos Parâmetros Curriculares Nacionais e da Base Nacional Comum Curricular para o Ensino Fundamental, percebeu-se que, no que diz respeito à legislação vigente, tudo parece ir bem, porém, não condiz com a realidade encontrada nas escolas públicas. Acredita-se que isso aconteça porque o que é acordado entre as autoridades competentes na elaboração de tais documentos não consegue abranger todas as regiões do país e isso se dá por diferentes causas, o que dificulta o acesso aos recursos, que reduzem os investimentos em formação continuada para os profissionais da educação.

Em relação ao currículo, Fontes, Contijo e Moreira (2019, p. 61) asseguram que: "o currículo escolar brasileiro segue, historicamente, uma organização disciplinar, linear e compartimentada. De acordo com nossos referenciais, esse modo de organizar o ensino é limitante, e não condiz com as necessidades educativas atuais".

Falta de investimento é uma constante no cotidiano de alunos e professores, e o questionamento da prática de ensino docente é corriqueiro, porém, é preciso que os governantes tenham compromisso para com a sociedade, principalmente no que se refere à educação, porque é o meio que o cidadão tem para superar suas dificuldades e melhorar sua condição social.

Acredita-se que, além do esforço do professor para oferecer a melhor prática de ensino, é indispensável que essas instituições ofereçam boas condições, oferecendo um espaço equipado com recursos tecnológicos, além de recursos humanos bem remunerados e preparados para o exercício da função. É o caso da formação docente: diante de constantes transformações que se observam nas formas de aprender e ensinar, a formação contínua do professor para atuar de maneira interdisciplinar é fundamental, pois ele precisa estar preparado para buscar melhorias para seus alunos, e para poder planejar de maneira mais flexível, podendo, inclusive, solicitar o auxílio de um colega de outra disciplina.

Enquanto esses recursos não forem possíveis de serem alcançados, entra em cena a figura do docente criativo, que com custo baixíssimo, pode oferecer um diferencial para a turma, como aconteceu com os pesquisadores no planejamento e execução da aula de frações, utilizando uma pizza confeccionada em papel cartão, uma simples brincadeira pode abrir espaço para o conhecimento.

Por fim, destaca-se que este é um tema bastante prazeroso de pesquisar, uma vez que elucidou algumas inseguranças, todavia, acredita-se que ainda há muito a investigar acerca da interdisciplinaridade, de suas propostas e obstáculos. É natural que, durante o desenvolvimento de um estudo, ele cresça acima do esperado, porém, em obediência às regras, fica uma sugestão para que, no futuro, a academia explore e amplie esse referencial teórico. 


\section{Referências}

BRASIL. Ministério da Educação. Secretaria de Educação Básica. Base Nacional Comum Curricular. Brasília, DF: MEC/SEB, 2017. Disponível em:

http://basenacionalcomum.mec.gov.br/images/BNCC El EF 110518 versaofinal site.pdf. Acesso em: 31 ago. 2021.

BRASIL. Ministério da Educação. Secretaria de Educação Fundamental. Parâmetros

Curriculares Nacionais de $\mathbf{5}^{\mathrm{a}}$ a $\mathbf{8}^{\mathrm{a}}$ séries: Matemática. Volume 3. Brasília: MEC/SEF, 1998.

Disponível em: http://portal.mec.gov.br/pnaes/195-secretarias-112877938/seb-educacao-basica2007048997/12657-parametros-curriculares-nacionais-5o-a-8o-series. Acesso em: 31 ago. 2021.

FELICETTI, Vera Lúcia. Linguagem na construção matemática. Revista Educação Por Escrito, Porto Alegre, v. 1, n. 1, jun. 2010. Disponível em:

https://revistaseletronicas.pucrs.br/ojs/index.php/porescrito/article/view/7121. Acesso em: 31 ago. 2021.

FERNANDES, Kênia de Souza Leão. A Interdisciplinaridade entre o Ensino da Matemática e a Geografia como Prática Facilitadora no Ensino Aprendizagem. In: ESPECIALIZAÇÃO EM EDUCAÇÃO MATEMÁTICA, 1., v. 1, n. 2, 2017. Anais [...]. Universidade Estadual de Goiás, Campus Cora Coralina, 2017. Disponível em:

https://www.anais.ueg.br/index.php/eem/article/view/9674. Acesso em: 31 ago. 2021.

FONTES, Líviam Santana; CONTIJO, Cleyton Hércules; MOREIRA, Geraldo Eustáquio. Currículo e Interdisciplinaridade na formação de professores de Matemática: o caso de uma universidade goiana. Revista Paranaense de Educação Matemática, Campo Mourão, PR, v. 8, n. 17, p. 61-78, 9 dez. 2019. Disponível em: http://revista.unespar.edu.br/index.php/rpem/article/view/618. Acesso em: 31 ago. 2021.

FREIRE, Paulo. Pedagogia da Autonomia: Saberes Necessários à Prática Educativa. 25. ed. São Paulo: Editora Paz e terra, 1996.

GARCIA, Joe. A Interdisciplinaridade Segundo Os Pcns. Revista de Educação Pública, Cuiabá, MT, v. 17, n. 35, p. 363-378, set./dez. 2008. Disponível em:

https://periodicoscientificos.ufmt.br/ojs/index.php/educacaopublica/article/view/494. Acesso em: 31 ago. 2021.

HADASSAH, Myriam. Resenha crítica sobre o capítulo VI do livro de LIMA, Sonia Regina Albano de. MÚSICA, EDUCAÇÃO E INTERDISCIPLINARIDADE: uma tríade em construção. São Paulo: Editora Cultura Acadêmica, 2016. Revista Interdisciplinaridade, São Paulo, SP, n. 13, p. 1-114, 3 out. 2018. Disponível em:

https://revistas.pucsp.br/index.php/interdisciplinaridade/article/view/39428. Acesso em: 31 ago. 2021.

LIBÂNEO, José Carlos. Tendências Pedagógicas na Prática Escolar. In: LUCHESI, C. C.

Filosofia da Educação. Série Formação do Professor. São Paulo: Cortez Editora, 1994, p.53-75.

OLIVEIRA, Shismênia. Pisa 2018 revela baixo desempenho escolar em Leitura, Matemática e

Ciências no Brasil. Portal do Ministério da Educação. 3 dez. 2019. Disponível em:

http://portal.mec.gov.br/component/content/article?id=83191:pisa-2018-revela-baixo-desempenhoescolar-em-leitura-matematica-e-ciencias-no-brasil. Acesso em: 1 set. 2021. 
SANTOMÉ, Jurjo Torres. Globalização e interdisciplinaridade: o currículo integrado. Porto Alegre: Editora Artes Médicas Sul Ltda, 1998.

SERENATO, Liliana Junkes. Aproximações interdisciplinares entre Matemática e Arte: resgatando o lado humano da Matemática. Orientador: José Carlos Cifuentes. 2008. 163f. Dissertação (Mestrado em Educação) - Universidade Federal do Paraná, Curitiba, 2008.

SILVA, Ana Lúcia Gomes da; FAZENDA, Ivani Catarina Arantes. O estudo da infância indígena: interdisciplinaridade na formação de professores para o diálogo com a arte. Revista Interdisciplinaridade, São Paulo, SP, n. 13, 3 out. 2018. Disponível em: https://revistas.pucsp.br/index.php/interdisciplinaridade/article/view/39422. Acesso em: 31 ago. 2021.

TAVARES, Dirce Encarnacion. Editorial. Revista Interdisciplinaridade, São Paulo, SP, n. 13, p. 1-114, 3 out. 2018. Disponível em:

https://revistas.pucsp.br/index.php/interdisciplinaridade/article/view/39421. Acesso em: 31 ago. 2021.

TOMAZ, Vanessa Sena. Interdisciplinaridade e aprendizagem da Matemática em sala de aula. Belo Horizonte: Autêntica Editora, 2008.

ZABALA, Antoni. Enfoque Globalizador e pensamento complexo: uma proposta para o currículo escolar. Porto Alegre: Editora Artmed, 2002. 